\title{
Depolarization of the hydrogen evolution reaction on cadmium electrodes in alkaline media
}

\author{
S. B. SAIDMAN, J. R. VILCHE, A. J. ARVIA \\ Instituto de Investigaciones Fisicoquimicas Teoricas y Aplicadas (INIFTA), Facultad de Ciencias Exactas, \\ Universidad Nacional de La Plata, Casilla de Correo 16, Sucursal 4, 1900 La Plata, Argentina
}

Received 16 November 1987 ; revised 8 January 1988

Depolarization of the hydrogen evolution reaction on high purity polycrystalline cadmium electrodes in alkaline media $\left(12 \leqslant \mathrm{pH} \leqslant 14\right.$ and $5 \leqslant T \leqslant 55^{\circ} \mathrm{C}$ ) produced by cathodization in the range of potential comprised between the $\mathrm{Cd} / \mathrm{Cd}(\mathrm{OH})_{2}$ electrode potential and the net HER potential under solution stirring conditions has been studied. The depolarization effect depends on the perturbing potential programme and it is little affected by the alkaline cation in solution. Results are discussed in terms of three concurrent reactions, namely the electrochemical formation of $\mathrm{Cd}(\mathrm{OH})_{2}$ and soluble $\mathrm{Cd}(\mathrm{OH})_{3}^{-}$, the HER and the electrocrystallization of cadmium renewing the fresh active sites for the HER, SEM micrographs of activated cadmium electrodes reveal a heterogeneous surface topography of the new cadmium layers.

\section{Introduction}

The HER on cadmium in alkaline media has been investigated principally in relation to characterizing the negative cadmium electrode in a nickel-cadmium battery cell [1-3]. The overall reaction for hydrogen generation on cadmium in alkaline solutions is

$$
2 \mathrm{H}_{2} \mathrm{O}+2 e^{-}=\mathrm{H}_{2}+2 \mathrm{OH}
$$

The reversible potential of this reaction at $\mathrm{pH} 12$ and $25^{\circ} \mathrm{C}$ is $-0.713 \mathrm{~V}$, a value which is only $7 \mathrm{mV}$ more negative than the equilibrium potential of the reaction:

$$
\mathrm{Cd}(\mathrm{OH})_{2}+2 e^{-}=\mathrm{Cd}+2 \mathrm{OH}^{-}
$$

which is $E=-0.706 \mathrm{~V}$ [4]. This means that, theoretically, the cadmium electrode should generate some hydrogen when the nickel-cadmium cell operates open circuited and even more during the cell charging process as the potential of the cadmium electrode becomes more negative due to the relatively high overvoltage associated with that process.

It is generally accepted that the HER on cadmium in $\mathrm{NaOH}, \mathrm{KOH}$ and $\mathrm{CsOH}$ solutions fits a $0.12 \mathrm{~V}$ decade $^{-1}$ Tafel slope, the transfer coefficient being close to $0.5[2,3,5]$. Under steady-state conditions, the dependence of HER on $\mathrm{pH}$ suggests a slow direct discharge of water and the small variations in the current density/potential curves were attributed mainly to the different sizes of cations which affect the double layer.

The analysis of the transient electrochemical behavour of freshly generated cadmium surfaces created by scratching shows that the maximum cathodic current density at fixed potentials under bare surface polarization is approximately independent of $\mathrm{pH}$, although the bare surface mixed potential obeys a Nernst type relationship [6]. It should also be noted that kinetic neasurements of HER on continuously renewed $(0021-891 X / 88 \$ 03.00+.12 \quad$ C) 1988 Chapman and Hall Ltd cadmium surfaces in both neutral and sulphuric acid solutions exhibit an overpotential decrease by approximately $0.10-0.15 \mathrm{~V}$ with respect to results obtained at non-renewed surfaces, probably due to a lower effective activation energy for the HER $[7,8]$

The cathodic currents on cadmium in $0.02-3.5 \mathrm{M}$ $\mathrm{KOH}$ present a transition region which lies between the large current density increase according to high cathodic overpotentials and the fast cathodic current density decrease preceding the active metal dissolution range [9]. As the potential of zero charge, $E_{z}$, of cadmium is located, presumably, within this transition region, it was suggested that the cathodic current behaviour can be related to the change in the adsorbed $\mathrm{H}_{2} \mathrm{O}-\mathrm{OH}^{-}$ion layer on the cadmium surface. The competition between the oxide/hydroxide film formation and HER rates can result in a partially covered cadmium surface. It is significant to note that a similar but more pronounced cathodic transition region has been observed for zinc in slightly alkaline solutions [10]. Results obtained by using the rotating ring disc technique [11] demonstrated that a $\mathrm{Cd}(\mathrm{OH})_{2}$ film is already present on cadmium as the HER is taking place. Likewise, the reduction of the $\mathrm{Cd}(\mathrm{OH})_{2}$ film takes place, at least partially, through the dissolved cadmium species. On the other hand, it is well known that the physicochemical properties of different sampies of $\mathrm{Cd}(\mathrm{OH})_{2}$ determine the rate of their chemical dissolution and the overpotential ratio for $\mathrm{Cd}(\mathrm{OH})_{2}$ electroreduction to HER [12]. The relative contribution of the HER varies strongly along the charging time.

Anodically formed oxide films on cadmium in $1-8 \mathrm{M}$ $\mathrm{NaOH}$ are mainly reduced at cathodic overpotentials in the range of $0.02-0.1 \mathrm{~V}$ with respect to $\mathrm{Cd} / \mathrm{Cd}(\mathrm{OH})_{2}$ [13], and at considerably higher overpotentials (approximately $0.3-0.5 \mathrm{~V}$ ), the reduction of the remaining surface film takes place. The latter process appears to be strongly influenced by the HER. Otherwise, the charg- 
ing plateau detected at high negative potentials in $0.1-7 \mathrm{M} \mathrm{KOH}$ solutions was assigned to the formation of either an intermetallic compound containing cadmium and potassium or a hydride [14]. These results illustrate the complexity of reactions which can occur on cadmium in the HER potential range in base solution and suggest the possibility of studying the mutual influence of the HER and $\mathrm{Cd} / \mathrm{Cd}(\mathrm{OH})_{2}$ electrode reactions under preset perturbing potential conditions.

\section{Experimental details}

The experimental set up was described in previous publications $[15,16]$. 'Specpure' cadmium (Johnson Matthey Chemicals Ltd) in the form of rotating discs $\left(0.20 \mathrm{~cm}^{2}\right.$ apparent area) axially mounted in PTFE holders were used as working electrodes. The disc surface was polished successively with 400 and 600 grade emery papers, 1.0 and $0.3 \mu \mathrm{m}$ grit aluminaacetone suspensions, thoroughly rinsed with triply distilled water and, finally, held for $5 \mathrm{~min}$ in the net HER region $(-1.66 \mathrm{~V}$ to $-1.56 \mathrm{~V}$ depending on solution $\mathrm{pH}$ ) to attain a reproducible electroreduced initial metal surface.

The counterelectrode was a large area $\mathrm{Pt}$ sheet. Potentials were measured against an SCE reference electrode properly shielded and connected through a Luggin-Haber capillary tip, but in the text they are referred to the NHE scale.

Runs were made in $x \mathrm{M} \mathrm{KOH}(0.01 \leqslant x \leqslant 1)$, $0.01 \mathrm{M} \mathrm{LiOH}$ and $0.01 \mathrm{M} \mathrm{NaOH}$ solutions in the $5-55^{\circ} \mathrm{C}$ range under purified nitrogen gas saturation. The electrolyte solutions were prepared from analytical grade (p.a. Merck) chemicals and triply distilled water; the latter was previously boiled to remove $\mathrm{CO}_{2}$. The current density/applied potential $(j / E)$ curves were recorded for electrodes either still $(\omega=0)$ or under rotation ( $300 \leqslant \omega \leqslant 3000$ r.p.m.) by employing the following perturbating potential programmes: (i) conventional single (STPS) or repetitive (RTPS) triangular potential sweeps between preset cathodic $\left(E_{\mathrm{s}, \mathrm{c}}\right)$ and anodic $\left(E_{\mathrm{s}, \mathrm{a}}\right)$ switching potentials at sweep rates (v) within the $0.0005 \leqslant v \leqslant 0.1 \mathrm{~V} \mathrm{~s}^{-1}$ range; and (ii) combined either STPS or RTPS with intermediate potential holding at $E_{\tau}$ for different times $(\tau)$. Electrochemical measurements were complemented with scanning electron microscopy using a Philips machine (505-B) with specimens previously subjected to triply distilled water and/or ethanol cleaning, drying and gold metallizing. Energy dispersive X-ray analysis of the electrode surfaces was carried out by using EDAX-PV 9100/60 equipment, and electron probe micro-analysis was performed employing a Microspec WDX-2A apparatus.

\section{Results}

The voltammogram of a cadmium electrode in stagnant $0.01 \mathrm{M} \mathrm{KOH} \mathrm{at} v=0.1 \mathrm{~V} \mathrm{~s}^{-1}$ between $E_{\mathrm{s}, \mathrm{c}}=-1.56 \mathrm{~V}$ and $E_{\mathrm{s}, \mathrm{a}}=0.24 \mathrm{~V}$ shows two anodic peaks (I and II), a complex cathodic peak (III) and a net cathodic cur-

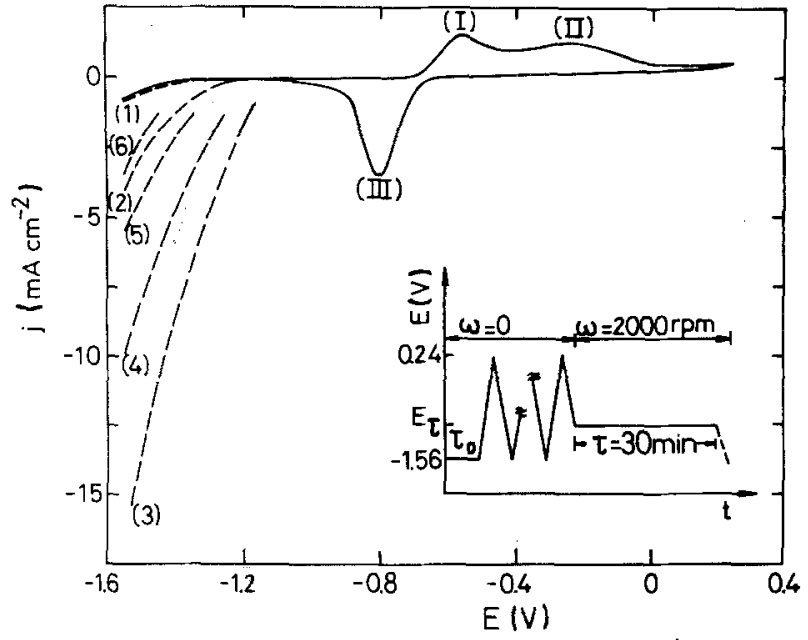

Fig. 1. Voltammogram (RTPS) run at $v=0.1 \mathrm{Vs}^{-1}, \omega=0$, between $E_{\mathrm{s}, \mathrm{c}}=-1.56 \mathrm{~V}$ and $E_{\mathrm{s}, \mathrm{a}}=0.24 \mathrm{~V}$ for $\mathrm{Cd} / 0.01 \mathrm{M} \mathrm{KOH}$ (full trace). Potentiodynamic response after potential holding at different $E_{\tau}$ for $\tau=30 \mathrm{~min}$, at $\omega=2000 \mathrm{r.p.m}$. (dashed traces). $E_{\mathrm{t}}=(1)-0.96 \mathrm{~V} ;$ (2) $-1.06 \mathrm{~V} ;$ (3) $-1.16 \mathrm{~V}$; (4) $-1.26 \mathrm{~V}$; (5) $-1.36 \mathrm{~V} ;(6)-1.46 \mathrm{~V}$.

rent at potentials lower than $-1.1 \mathrm{~V}$ (Fig. 1). Peak I initiates at a potential very close to the equilibrium potential of the $\mathrm{Cd} / \mathrm{Cd}(\mathrm{OH})_{2}$ electrode $(E=-0.706 \mathrm{~V}$ at $\mathrm{pH}$ 12). Peak II is located at $-0.25 \mathrm{~V}$.

The voltammogram depicted in Fig. 1, particularly for peaks I, II and III changes little during potential cycling and it becomes practically independent of the solution stirring conditions. In addition, during a few initial cycles, under stirring, the cathodic current at $E<-1.1 \mathrm{~V}$ can exceed that observed after prolonged cycling but these changes in the voltammogram are rather irreproducible uniess a potential holding at $E_{t}$ $\left(-1.42 \leqslant E_{\tau} \leqslant-0.96 \mathrm{~V}\right)$, is inserted into the potential scan, for $\tau=30 \mathrm{~min}$ at $\omega=2000$ r.p.m. This combined potential sweep potential step treatment produces an appreciable increase in cathodic current at potentials lower than $-1.2 \mathrm{~V}$. This effect depends strongly on the $E_{\tau}$ value (see dashed curves in Fig. 1), the maximum enhancement appearing for $E_{\tau}=$ $-1.16 \mathrm{~V}$. Under these conditions the cathodic current

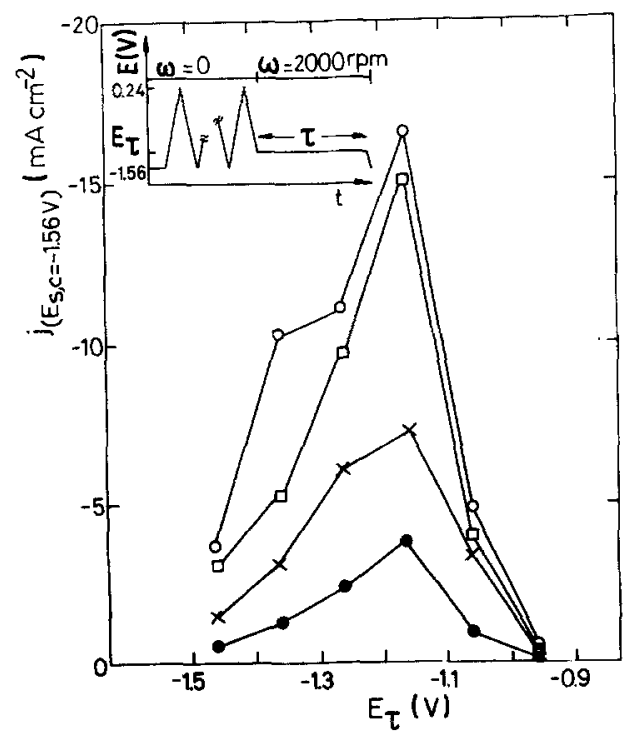

Fig. 2. Dependence of current density at $E_{\mathrm{s}, \mathrm{c}}=-1.56 \mathrm{~V}$ on $E_{\tau}$ for different holding times $\tau$ obtained from the potential programme indicated in the figure for $\mathrm{Cd} / 0.01 \mathrm{M} \mathrm{KOH} . v=0.1 \mathrm{~V} \mathrm{~s}^{-1} \cdot \tau=(\bullet)$ $3 \mathrm{~min}$; (x) $10 \mathrm{~min}$; ( $\square$ ) $30 \mathrm{~min}$; (O) $60 \mathrm{~min}$. 


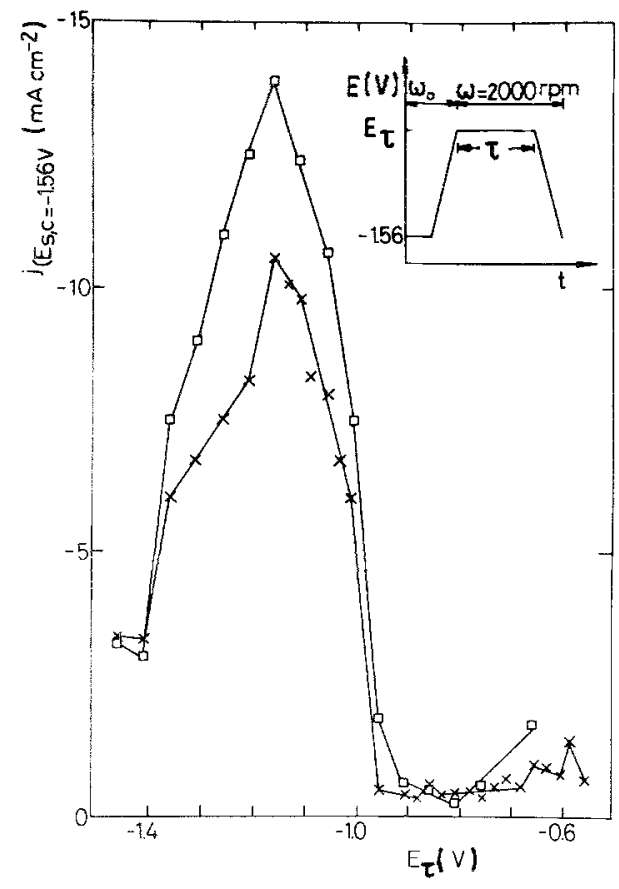

Fig. 3. Dependence of current density at $E_{\mathrm{s}, \mathrm{c}}=-1.56 \mathrm{~V}$ on $E_{\tau}$ for a constant $\tau=10 \mathrm{~min}$ and $\omega_{0}=0(x)$ and $\omega_{0}=2000$ r.p.m. ( $\square$ ) obtained from the potential programme shown in the figure for $\mathrm{Cd} / 0.01 \mathrm{M} \mathrm{KOH}, v=0.1 \mathrm{Vs}^{-1}$

measured from $E_{\tau}$ downwards greatly exceeds that recorded during the first cycles. Correspondingly, the cathodic current at $E_{\mathrm{s}, \mathrm{c}}=-1.56 \mathrm{~V}$ resulting from the potential holding at $E_{\tau}$ for different times, $\tau$, increases with $\tau$ (Fig. 2). The inclusion of the potential step at $E_{\tau}$ produces practically no voltammetric changes in the potential ranges of peaks I, II and III.

Similar results are obtained by using a single sweep potential programme depicted in Fig. 3 with $E_{s, a}=$ $E_{z}$, although the magnitude of the cathodic current obtained at $E_{\mathrm{s}, \mathrm{c}}=-1.56 \mathrm{~V}$ in the reverse scan appears to be slightly affected by $\omega_{0}$, the rotation speed of the working electrode and the initial positive going potential excursion. Furthermore, the value of $\omega$ set for the potential holding at $E_{\tau}=-1.16 \mathrm{~V}$ determines the magnitude of the cathodic current at $E_{\mathrm{s}, \mathrm{c}}$ in the subsequent reverse scan (Fig. 4). At $E_{\mathrm{s}, \mathrm{c}}=-1.56 \mathrm{~V}$ the cathodic current density increases linearly with the square root of $\omega, \omega$ being the rotation speed of the working electrode during the potential step and subsequent reverse potential scan. The extrapolated value of $j$ for $\omega \rightarrow 0$ equals $6.6 \mathrm{~mA} \mathrm{~cm}^{-2}$, which is about $60 \%$ of the current density detected at $\omega=3000$ r.p.m. However, at $\omega=0$, for the potential holding at $E_{\tau}=$ $-1.16 \mathrm{~V}$, practically no enhancement of the cathodic current at $E_{\mathrm{s}, \mathrm{c}}=-1.56 \mathrm{~V}$ is observed under similar experimental conditions.

The cathodic current enhancement at $E_{\mathrm{s}, \mathrm{c}}=-1.56 \mathrm{~V}$ remains even for those electrodes which have been removed from the electrolyte, rinsed with triply distilled water, dried, maintained at room atmosphere for $10 \mathrm{~min}$ and later re-immersed in the electrolyte to measure the current at $E_{\mathrm{s}, \mathrm{c}}$.

The increase in cathodic current resulting from the potential stepping at $E_{\tau}$ for the time $\tau$, depends on

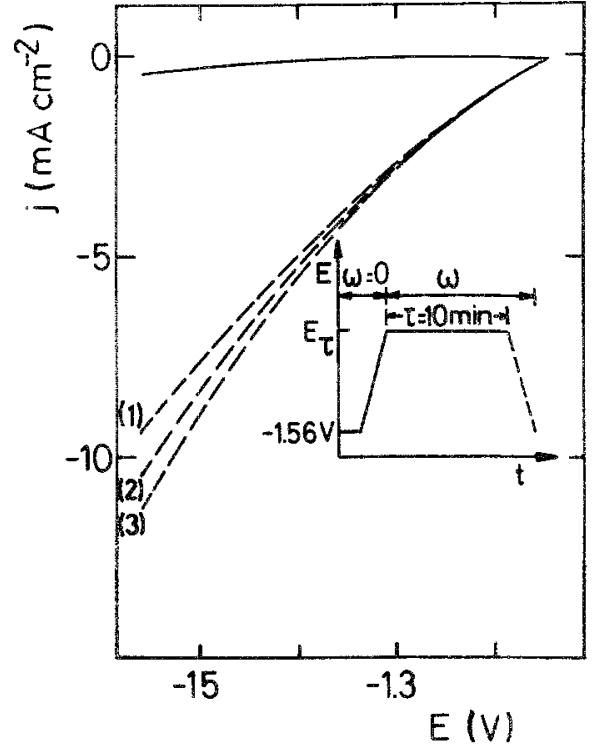

Fig. 4. Influence of $\omega$ on the voltammogram recorded after a potential holding at $E_{\tau}=-1.16 \mathrm{~V}$ for $\tau=10 \mathrm{~min}$ from the potential programme depicted in the figure for $\mathrm{Cd} / 0.01 \mathrm{M} \mathrm{KOH}$. $v=0.1 \mathrm{Vs}^{-1} . \omega=$ (1) 1000 r.p.m.; (2) 2000 r.p.m.; (3) 3000 r.p.m.

both $E_{\tau}$ and $\tau$ (Fig. 5). For $E_{\tau}$ values in the $-1.06 \leqslant$ $E_{\tau} \leqslant-1.36 \mathrm{~V}$ range the increase in cathodic current implies an induction time $\tau$, which changes according to $E_{\tau}$ as shown in Fig. 5. It is clear that beyond $\tau^{*}$ the cathodic current at $E_{t}$ increases with a linear $\log j$ vs $\log t$ relationship whose slope is about $0.84 \pm 0.08$. The minimum value of $\tau^{*}$, which is about 3 min, results for $E_{\tau}=-1.16 \mathrm{~V}$. It should be noticed that for $E_{\tau}=$ $E_{\mathrm{s}, \mathrm{c}}=-1.56 \mathrm{~V}$ the cathodic current remains practically at the steady state value, at least for potential holding times of about $90 \mathrm{~min}$.

Voltammetric runs carried out at $v=0.0005 \mathrm{~V} \mathrm{~s}^{-1}$ between $E_{\mathrm{s}, \mathrm{c}}=-1.56 \mathrm{~V}$ and different $E_{\mathrm{s}, \mathrm{d}}$ values, under stirring, show an ill-defined cathodic peak at approximately $-1.26 \mathrm{~V}$ during the positive potentialgoing excursion (Fig. 6). In addition, during the reverse scan a considerable increase in cathodic current is noticed as $E_{\mathrm{s}, \mathrm{a}}$ exceeds the potential range of the new cathodic peak. But as $E_{\mathrm{s}, \mathrm{a}}$ is set within the poten-

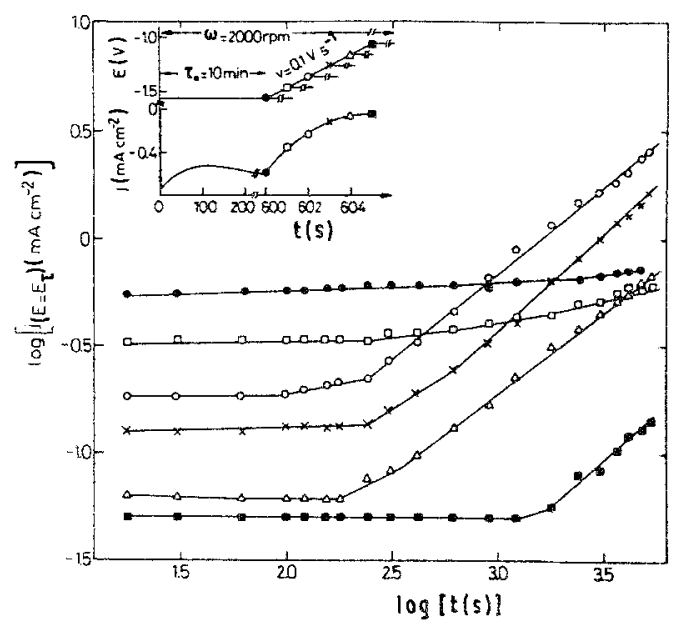

Fig. 5. Dependence of the current density at different $E$, on the holding time from the potential programme indicated in the figure for $\mathrm{Cd} / 0.01 \mathrm{M} \mathrm{KOH}$. The variation of $j$ before the potential holding is also included. $E_{\tau}=(\mathrm{E})-1.06 \mathrm{~V} ;(\Delta)-1.16 \mathrm{~V} ;(\mathrm{x})-1.26 \mathrm{~V}$ (०) $-1.36 \mathrm{~V} ;(\square)-1.46 \mathrm{~V} ;(\bullet)-1.56 \mathrm{~V}$. 


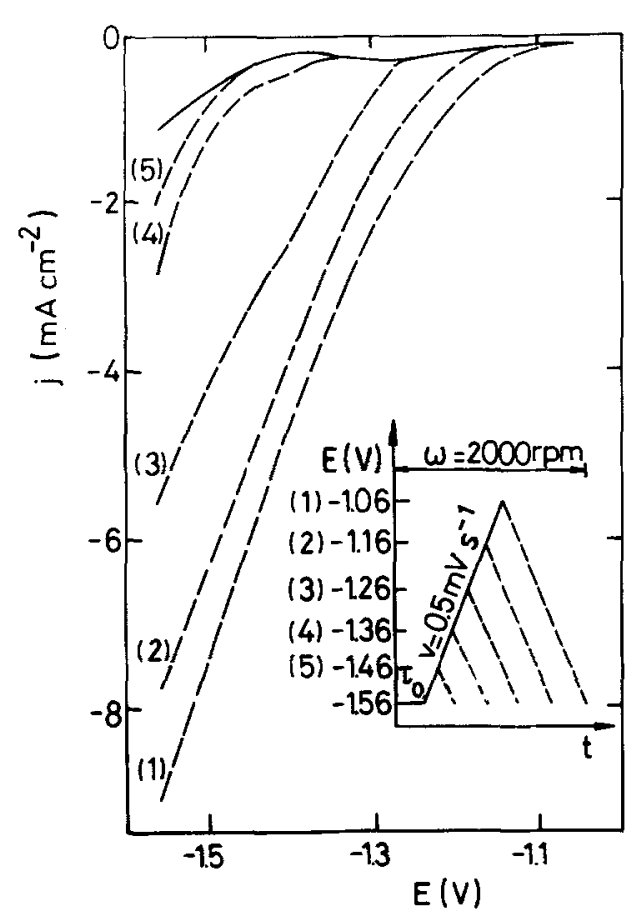

Fig. 6. Influence of $E_{\mathrm{s}, \mathrm{a}}$ on the voltammograms obtained at $v=$ $0.0005 \mathrm{~V} \mathrm{~s}^{-1}$ and $\omega=2000$ r.p.m. from $E_{\mathrm{s}, \mathrm{c}}=-1.56 \mathrm{~V}$ for $\mathrm{Cd} / 0.01 \mathrm{M} \mathrm{KOH}$.

tial range of the new cathodic peak, the reverse scan exhibits a small current hump at approximately $-1.4 \mathrm{~V}$, largely overlapping the cathodic current.

For the sake of comparison additional measurements were performed at $\mathrm{pH} 12$ using $\mathrm{LiOH}, \mathrm{KOH}$ and $\mathrm{NaOH}$ and in $1 \mathrm{M} \mathrm{KOH}$. The strong influence of the perturbing potential programme on the cathodic current enhancement appears to be little affected by the nature of the cation. At $\mathrm{pH} 12$ the cathodic current at $E_{\mathrm{s}, \mathrm{c}}=-1.56 \mathrm{~V}$, resulting from $E_{\tau}=-1.16 \mathrm{~V}, \tau=$ $10 \mathrm{~min}$ and $\omega=1000$ r.p.m., in the $5-55^{\circ} \mathrm{C}$ range fits an Arrhenius plot which is practically independent of the cation in solution. The apparent activation energy is $\Delta E^{*} \approx 33 \mathrm{~kJ} \mathrm{~mol}^{-1}$ (Fig. 7).

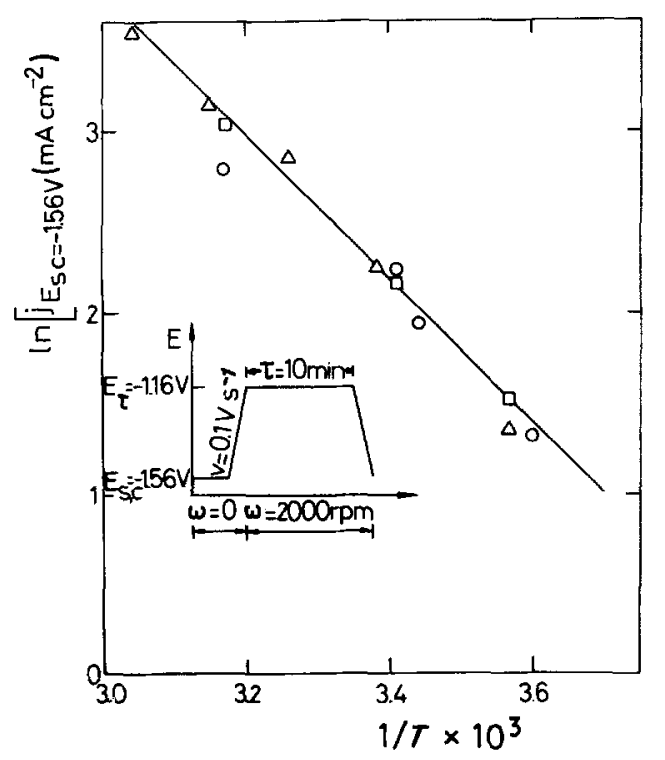

Fig. 7. Arrhenius plot for the current density at $E_{\mathrm{s}, \mathrm{c}}=-1.56 \mathrm{~V}$ at different temperatures in the $5-55^{\circ} \mathrm{C}$ range from the potential programme indicated in the figure for $0.01 \mathrm{M} \mathrm{KOH}(\Delta), 0.01 \mathrm{M} \mathrm{NaOH}$

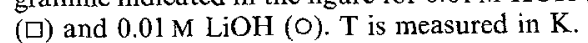

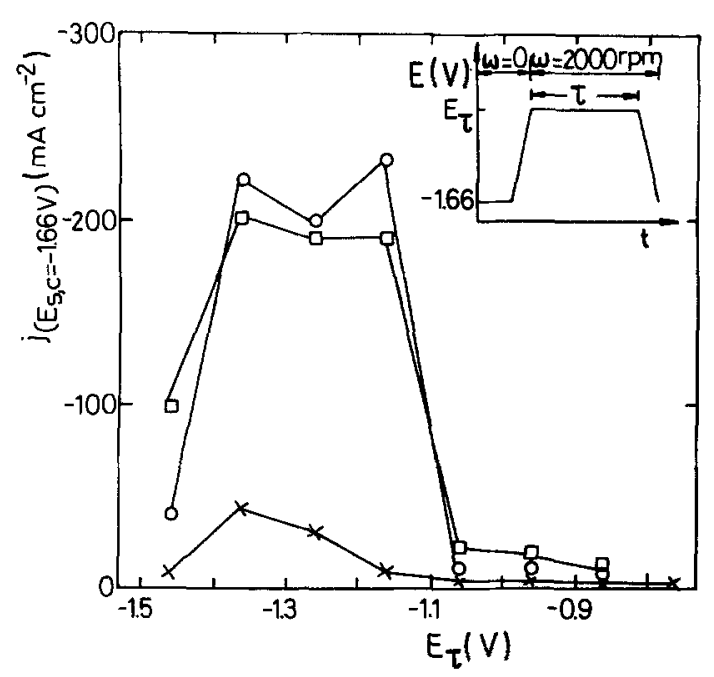

Fig. 8. Dependence of current density at $E_{s, \mathrm{c}}=-1.66 \mathrm{~V}$ on $E_{\mathrm{\tau}}$ at different $\tau$ values from the potential programme shown in the figure for $\mathrm{Cd} / 1 \mathrm{M} \mathrm{KOH} . v=0.1 \mathrm{~V} \mathrm{~s}^{-1} . \tau=(x) 10 \mathrm{~min} ;(\square) 30 \mathrm{~min} ;(0)$ $60 \mathrm{~min}$.

Under comparable experimental conditions the cathodic current enhancement in $1 \mathrm{M} \mathrm{KOH}$ is considerably greater than in $0.01 \mathrm{M} \mathrm{KOH}$, although in the former case results are less reproducible. The magnitude of the cathodic current at $E_{\mathrm{s}, \mathrm{c}}=-1.66 \mathrm{~V}$ after a potential holding at different $E_{\tau}$ values for various times $\tau$ up to $60 \mathrm{~min}$, shows that a large increase of $j$ results for $-1.36 \leqslant E_{\tau} \leqslant-1.16 \mathrm{~V}$, the maximum value of $j$ being for $E_{\imath}=-1.16 \mathrm{~V}$ at large $\tau$ (Fig. 8). It should be noticed that results shown in Fig. 2 also suggest a similar influence of $E_{\tau}$ at large holding times for $\mathrm{pH} 12$.

The current read at the hydrogen overpotential range (referred to the equilibrium potential of the hydrogen electrode in the solution) $0.4 \leqslant \eta_{\mathrm{c}} \leqslant 0.7 \mathrm{~V}$ in $1 \mathrm{M} \mathrm{KOH}$ from the voltammogram at $v=0.1 \mathrm{~V} \mathrm{~s}^{-1}$ for an activated electrode, at $E_{\tau}=-1.16 \mathrm{~V}$ for $\tau=60 \mathrm{~min}$, exhibits an enhancement in the apparent cathodic current density of about 1.5 decades as compared to that obtained in $6 \mathrm{M} \mathrm{KOH}$ under steady state conditions at the same $\eta_{\mathrm{c}}$ range [2].

SEM micrographs of Cd electrodes in $0.01 \mathrm{M} \mathrm{KOH}$, previously held at $E_{\tau}=-1.36 \mathrm{~V}$, for $\tau=180 \mathrm{~min}$ (that is at the value of $E_{\tau}$ at which the largest cathodic current enhancement is produced (Fig. 5)), show a clear heterogeneous change in surface topography consistent with the electrocrystallization of a Cd overlayer, which eliminates the typical pattern of the mechanically polished Cd surface (Fig. 9). Energy dispersive X-ray analysis and electron probe microanalysis indicate that $\mathrm{Cd}$ is the only component at the activated electrode surface.

\section{Discussion}

The HER activation effect for $\mathrm{Cd}$ in alkaline solutions can be summarized as follows.

(i) The effect is produced by holding the applied potential in a definite range going from the potential where the electroreduction of the oxide layer is apparently down to approximately $-1.5 \mathrm{~V}$.

(ii) For a constant potential holding time, the effect 

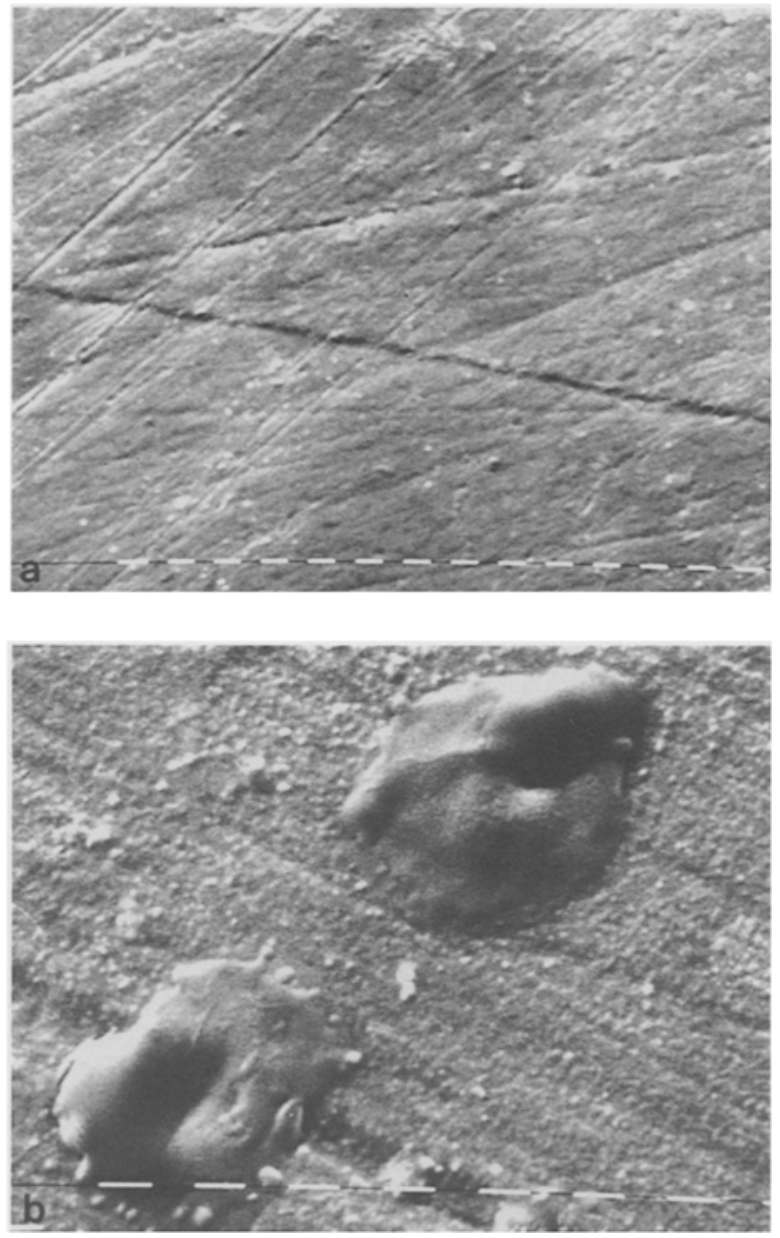

Fig. 9. Scanning electron micrographs of a polished cadmium (a) and a cadmium specimen after potential holding at $E_{\tau}=-1.36 \mathrm{~V}$ for $\tau=180 \mathrm{~min}$ in $0.01 \mathrm{M} \mathrm{KOH}$ (b). Scale $1 \mu \mathrm{m}$.

becomes slightly more marked as $\omega$ increases; although stirring is essential to produce the effect its actual magnitude is not of a great importance as can be seen in Fig. 4. The small stirring effect can only be attributed to hydrogen bubble removal from the interface.

(iii) Independently of the value of $\tau$ at $\mathrm{pH} \mathrm{12,} \mathrm{there}$ is a common optimal $E_{\tau}$ value of $-1.16 \mathrm{~V}$ for producing a maximum increase in cathodic current density at $-1.56 \mathrm{~V}$ (Fig. 2).

(iv) The activation effect involves an induction period $\left(\tau^{*}\right)$, which goes through a minimum value for $E_{\tau}=-1.16 \mathrm{~V}$ (Fig. 5). When the induction period is exceeded the kinetics of current increase fit a $j$ vs $t^{n}$ relationship for $E=E_{t}$, where $n$ lies close to one.

(v) There is a well-defined potential range $(-1.05$ to $-1.45 \mathrm{~V}$ ) where the activation effect occurs (Figs 2 and 8 ). At potentials outside this critical region no effect on HER can be noticed.

(vi) SEMs of activated cadmium electrodes show considerable differences in the characteristics of the surface morphology. Energy dispersive X-ray analysis and electron-probe micro-analysis data confirm that the surface is exclusively cadmium.

(vii) The HER activation effect increases with the alkaline hydroxide concentration.

The explanation of these intriguing results must be consistent with the facts that no increase in the anodic
Table 1. Redox potentials of some reacitons relevant for the present work

\begin{tabular}{lll}
\hline Reaction & $E^{0}(V)$ & $E_{\text {phit2 }}(V)$ \\
\hline (1) $2 \mathrm{H}_{2} \mathrm{O}+2 e^{-} \rightleftarrows 2 \mathrm{OH}^{-}+\mathrm{H}_{2}$ & -0.831 & -0.713 \\
(2) $\mathrm{Cd}(\mathrm{OH})_{2}+2 e^{-} \rightleftarrows \mathrm{Cd}+2 \mathrm{OH}^{-}$ & $-0.824[4]$ & -0.706 \\
(3) $\mathrm{Cd}(\mathrm{OH})_{3}^{-}+2 e^{-} \rightleftarrows \mathrm{Cd}+3 \mathrm{OH}^{-}$ & $-0.668[4]$ & $-0.668^{*}$
\end{tabular}

* Calculated for $\mathrm{Cd}(\mathrm{OH})_{2}$ saturation condition [22]

oxide layer formation charge is noticed for an activated electrode, that the apparent Arrhenius plots exhibit a slope which is practically independent of the degree of activation, and that the nature of the cation is, in principle, irrelevant (Fig. 7).

From the thermodynamic standpoint it is convenient to consider the equilibria involved in the potential range where the HER depolarization effect is noticed (Table 1). In addition, from data reported in the literature [17-19] for the value of the potential of zero charge, $E_{\mathrm{z}}$ for $\mathrm{Cd}$ in base solutions can be estimated as $<-1.1 \mathrm{~V}$. Hence, in the potential range where the depolarization effect is observed, one would expect that the $\mathrm{Cd}$ electrode surface is largely covered by $\mathrm{OH}^{-}$ions, a situation which is assisted by the local increase in alkalinity resulting from the HER itself. Otherwise, according to the thermodynamics, in the potential range associated with the HER depolarization effect, the cadmium proper electrode reactions become feasible. Based on SEM micrographs the Cd surface consists of a heterogeneous surface involving anodic and cathodic patches analogous to a spontaneous corrosion process, which in turn influences the HER. This arises from electrodissolution and chemical dissolution of $\mathrm{Cd}$ as $\mathrm{Cd}(\mathrm{OH})_{2}$ and $\mathrm{Cd}(\mathrm{OH})_{3}^{-}$at anodic surface sites and the electrodeposition of $\mathrm{Cd}$ at cathodic surface sites which continually renew the $\mathrm{Cd}$ surface, causing an overpotential decrease for the HER. Reactions involving $\mathrm{Cd}$ species are likely to involve equilibrium conditions, whereas the HER behaves as a clear irreversible reaction. In this sense, the effect could be similar to that reported for the renewed $\mathrm{Cd}$ surfaces in neutral and acid solutions $[7,8]$.

The influence of stirring on the depolarization effect can be explained in terms of $\mathrm{H}_{2}$ bubble formation. This process implies a nucleation and growth of bubbles at a certain distance from the electrode surface. Local bubble formation acts against the depolarization effect. This is clearly noticed on increasing the applied cathodic potential where bubble formation destroys the quasi-steady situation reached for the formation of $\mathrm{Cd}$ species and its electrodeposition in the -1.1 to $-1.4 \mathrm{~V}$ potential range where the activation of the HER is noticed. On the other hand, a similar situation arises even at lower potentials under no stirring due to the accumulation of bubbles. Therefore, the maximum depolarization effect of the HER results from a compromise between the potential applied to the electrode, where the above-mentioned concurrent reactions takes place, and the hydrodynamic conditions prevailing at the electrode surface which modify the 
nucleation and growth process for $\mathrm{H}_{2}$ bubble formation $[20,21]$.

\section{Acknowledgement}

This work was financially supported by the Consejo Nacional de Investigaciones Cientificas y Técnicas, the Comisión de Investigaciones Cientificas de la Provincia de Buenos Aires, and the Multinational Chemistry Programme of the Organization of American States.

\section{References}

[I] P. C. Milner and V. B. Thomas, in 'Advances in Electrochemistry and Electrochemical Engineering' (edited by C. W. Tobias), Interscience, New York (1967) Vol. 5, pp. 1-86.

[2] S. Gross and R. J. Glocking, 'The cadmium electrode. A review of the status of research', Final Report of Boing Aerospace Company, Document D180-19046-2 (1976)

[3] R. Barnard, J. Appl. Electrochem. 11 (1981) 217.

[4] Y. Okinaka, in 'Standard Potentials in Aqueous Solution' (edited by A. J. Bard, R. Parsons and J. Jordan), Marcel Dekker, New York (1985) pp. 257-265.

[5] A. J. Appleby, H. Kita, M. Chemla and G. Bronoel, in 'Encyclopedia of Electrochemistry of the Elements' (edited by A. J. Bard), Marcel Dekker, New York, (1982) Vol. IX, pp. 383-547

[6] G. T. Burstein, J. Electrochem. Soc. 130 (1983) 2133.

[7] Kh. I. Noninski and I. P. Ivanov, Khim. Ind. Sofia 47 (1975) 304

[8] Kh. I. Noninski, I. P. Ivanov and M. P. Vasil'eva-Dimova, Khim. Ind. Sofia 49 (1977) 74.

[9] I. Sanghi, S. Visvanathan and S. Ananthanarayanan, Electrochim. Acta 3 (1960) 65.

[10] I. Sanghi and M. Fleischmann, Electrochim. Acta 1 (1959) 161 .

[11] Y. Okinaka, J. Electrochem. Soc. 117 (1970) 289.

[12] I. A. Kazarinov, N. V. Kadnikova and L. A. L'vova, Elektrokhimiya 16 (1980) 809.

[13] Yu. I. Obedkov and L. A. L'vova, Elektrokhimiva 10 (1974) 341

[14] V. P. Galushko, E. F. Zavgorodnyaya, N. V. Podolskaya and Yu. P. Rocak, Elekirokhimiya 8 (1972) 1216.

[15] S. B. Saidman, M. Lopez Teijelo, J. R. Vilche and A. J. Arvia, Ann. Bras. Eletroquim. Eletroanal. 4 (1984) 141.

[16] S. B. Saidman, J. R. Vilche and A. J. Arvia, Electrochim. Acta 32 (1987) 395.

[17] S. Trasatti, J. Electroanal. Chem. 123 (1981) 121.

[18] S. Trasatti, J. Electroanal. Chem. 172 (1984) 27.

[19] I. A. Bagotskaya and A. V. Shlepakov, Elektrokhimiya 16 (1980) 565 .

[20] N. Ibl and J. L. Venczel, Metalloberfäche 24 (1970) 365.

[21] C. I. Elsner and S. L. Marchiano, J. Appl. Electrochem. 12 (1982) 735 .

[22] R. M. Smith and A. E. Martell, in 'Critical Stability Constants' Plenum Press, New York (1976) Vol. 4, p. 9 